\title{
Communication
}

\section{Recent advances in the superovulation in cattle}

\author{
Reuben J. MAPLETOFT ${ }^{\mathrm{a}, \mathrm{b} *}$ Kristina BenNetT STEWARD $^{\mathrm{b}}$, \\ Gregg P. ADAMS ${ }^{\mathrm{a}}$ \\ ${ }^{a}$ Western College of Veterinary Medicine, University of Saskatchewan, Saskatoon, \\ Saskatchewan, S7N 5B4, Canada \\ ${ }^{\mathrm{b}}$ Bioniche Animal Health, Bellville, ON K8N 5J2, Canada
}

\begin{abstract}
The variability in the superovulatory response continues to be one of the most frustrating problems with embryo transfer in cattle. The removal of LH from pituitary extracts has tended to reduce the variability in response, and several studies involving the use of the purified porcine pituitary extract, Folltropin ${ }^{\circledR}-\mathrm{V}$ are reviewed. The major source of variability in the superovulatory response in cattle is the status of ovarian follicles at the time of initiation of gonadotrophin treatments. Data support the benefits of initiating gonadotrophin treatments at the time of emergence of a follicular wave. Incorporation of techniques designed to control follicular wave dynamics, such as follicular ablation, or treatment with estradiol/progesterone, have reduced the variability caused by treating cows at different stages of follicular development, and at the same time improved response by taking advantage of endogenous recruitment and selection mechanisms. New protocols offer the convenience of being able to initiate gonadotrophin treatments quickly and at a self-appointed time, without the necessity of estrus detection and without sacrificing response. Methods can be used for repeated superstimulation of donor animals at 25 to 30 day intervals, without regard to estrus detection or stage of the estrous cycle, and without compromising embryo production.
\end{abstract}

superstimulation / gonadotrophin / FSH / LH / follicular waves / embryo transfer / cattle

\section{INTRODUCTION}

The objective of superstimulatory treatments in the cow is to obtain a maximum number of fertilized and transferable embryos with a high probability of producing pregnancies [6]. Wide ranges in superovulatory response and embryo yield have been detailed in several reviews of com-

* Correspondence and reprints

E-mail: reuben.mapletoft@usask.ca mercial embryo transfer records. In a report of 2048 beef donor collections, a mean of 11.5 ova/embryos with 6.2 transferable embryos were collected from each cow [27]. However, the variability was great in both the superovulatory response and embryo quality; $24 \%$ of the collections did not produce viable embryos, $64 \%$ produced fewer 
than average numbers of transferable embryos and $30 \%$ yielded $70 \%$ of the embryos. Embryo recovery from 987 dairy cows yielded slightly fewer ova/embryos and there was similar variability in response among animals [25]. The high degree of unpredictability in the superovulatory response creates problems affecting both the efficiency and profitability of embryo transfer programs [24].

Variability in ovarian response has been related to differences in superovulatory treatments, such as gonadotrophin preparation, batch and total dose, duration and timing of treatment, and the use of additional hormones in the superovulatory scheme. Additional factors, which may be more important sources of variability, are inherent to the animal and its environment. These factors may include nutritional status, reproductive history, age, season, breed, ovarian status at the time of treatment and the effects of repeated superovulation. While considerable recent progress has been made in the field of bovine reproductive physiology, factors inherent to the donor animal which affect superovulatory response are only partially understood. The purpose of this review is to address the practical aspects of bovine superovulation with a view to simplifying superstimulatory procedures, improving responses and reducing variability; in the interest of space, reference to review articles will be done as much as possible.

\section{GONADOTROPHINS \\ AND SUPEROVULATION}

Factors associated with the administration of exogenous gonadotrophins affecting superovulatory response include source, batch and biological activity of the gonadotrophin [36]. We have investigated the biological activity of gonadotrophins and the effect that FSH and LH activities in gonadotrophin preparations have on the superovulatory response in the cow. We have also investigated the use of the highly purified porcine pituitary extract (Folltropin ${ }^{\circledR}-\mathrm{V}$; Bioniche Animal Health, Bellville, ON, Canada) $[7,20]$. Pertinent research on the biological activity of gonadotrophins and how this affects superovulatory response in the cow will be reviewed.

Three different types of gonadotrophins have been used to induce superovulation in the cow; gonadotrophins from extracts of porcine or other domestic animal pituitaries, equine chorionic gonadotrophin (eCG) and human menopausal gonadotrophin (hMG) $[5,36]$. Prostaglandin (PGF) or its analogues have been used for the induction of luteolysis in a superstimulatory regimen, to allow for precise timing of the onset of estrus and ovulation. The biological half-life of FSH in the cow has been estimated to be $5 \mathrm{~h}$ or less so it must be injected twice a day to successfully induce superovulation [33]. The usual regimen is 4 or 5 days, twice daily treatments of FSH with a total dose of 28 to $50 \mathrm{mg}$ (Armour) of a crude pituitary extract (FSH-P) or $400 \mathrm{mg}$ NIH-FSH-PI of the purified pituitary extract, Folltropin ${ }^{\circledR}-\mathrm{V}$. Forty-eight or $72 \mathrm{~h}$ after initiation of the treatment, PGF is injected to induce luteolysis. Estrus occurs between 36 and 48 h, with ovulation 24 and $36 \mathrm{~h}$ later.

Equine chorionic gonadotrophin is a complex glycoprotein with both FSH and LH activity [35]. It has been shown to have a half-life of $40 \mathrm{~h}$ in the cow and persists for up to 10 days in bovine circulation; thus it is normally injected once followed by a PGF injection, $48 \mathrm{~h}$ later [18]. The long halflife of eCG causes continued ovarian stimulation, unovulated follicles, abnormal endocrine profiles and reduced embryo quality $[32,34,41]$. These problems have been largely overcome by the intravenous injection of antibodies to eCG at the time of the first insemination, 12 to $18 \mathrm{~h}$ after the onset of estrus [18, 21]. Recommended doses of eCG range from 1500 to $3000 \mathrm{IU}$, with 2500 IU by intramuscular injection commonly chosen.

Monniaux et al. [33] treated a group of cows with $2500 \mathrm{IU}$ eCG and another with 
$50 \mathrm{mg}$ (Armour) FSH-P and observed that ovulation rate and the percentage of cows with more than 3 transferable embryos was slightly higher with FSH-P than eCG. Although these results were in agreement with those of Elsden et al. [19] others have found no differences between pituitary FSH extracts and eCG [5, 22, 30]. Endocrine studies have revealed that eCG-treated animals more frequently had abnormal LH and progesterone profiles than did the FSHtreated cows [23, 32]. These were associated with reductions in both ovulation and fertilization rate [15]. In a study of cows repeatedly superstimulated at 60 to 90 day intervals over 1 year, we found no differences in the superovulatory response between two different pituitary extracts (Folltropin ${ }^{\circledR}-\mathrm{V}$ or FSH-P) and eCG with or without a monoclonal antibody to eCG (Neutra-PMSG; Intervet, Boxmeer, Holland) administered at the time of the first insemination [30]. However, the numbers favored Folltropin ${ }^{\circledR}$-V and eCG with Neutra-PMSG. Others have made similar observations [22].

Although folliculogenesis in mammals requires both $\mathrm{FSH}$ and $\mathrm{LH}$, there is a considerable variability in FSH and LH content of crude gonadotrophin preparations. Radioreceptor assays and in vitro bioassays have revealed variability in both the FSH and LH activity of eCG, not only among pregnant mares, but also between bleedings in the same mare at different times during gestation [35]. We have also examined the effects of the FSH/LH ratio of eCG on the superovulatory responses with immature rats and found that there was a positive correlation between the ratio of $\mathrm{FSH} / \mathrm{LH}$ activity and superovulatory response. Lower ratios of FSH/LH activity appeared to reduce ovulatory response in rats and additional $\mathrm{LH}$, when added to the eCG reduced superovulatory response in cows $[35,36]$.

Purified pituitary extracts with low LH contamination have been reported to improve the superovulatory response in cattle. Chupin et al. [16] superstimulated three groups of dairy cows with an equivalent amount of $450 \mu \mathrm{g}$ pure pFSH and varying amounts of $\mathrm{LH}$, and showed that the mean ovulation rate and the number of recovered and transferable embryos increased as the dose of LH decreased. They observed that as $\mathrm{LH}$ activity increased, the dose of $\mathrm{FSH}$ required to induce an acceptable response also increased. It has been suggested that embryo quality may be adversely influenced by high LH levels during superstimulation due to the premature activation of the oocyte [34].

We have completed several experiments with the LH-reduced Folltropin ${ }^{\circledR}$-V utilizing several different total doses, ranging from 100 to $900 \mathrm{mg}$ of NIH-FSH-P1 activity [5, 20]. There was no evidence of detrimental effects of the dose on embryo quality. Ovulation rates continued to increase to $400 \mathrm{mg}$ NIH-FSH-P1 (40 mg Armour) and did not increase beyond that dose. At the same time fertilization rate and transferable embryo rate remained constant throughout the dose range used. On the contrary, doubling the dose of LH-rich preparations (FSH-P or $\mathrm{hMG}$ ) resulted in significantly reduced fertilization rates and percentages of transferable embryos [5]. Collectively, data support the hypothesis that the detrimental effects of high doses of pituitary gonadotrophins on ova/embryo quality is due to an excess of LH.

Recently, we investigated the long-term safety of Folltropin ${ }^{\circledR}-\mathrm{V}$ in a retrospective study involving 1949 donor cows and their offspring i.e., second and third generation donor cows which were a result of superovulation and embryo transfer. Reproductive safety was examined by calculating the number of viable embryos collected from each cow and the number of normal calves born to cows that had been previously superstimulated with Folltropin ${ }^{\circledR}$-V. Embryological safety was measured by the number of live calves produced from superovulation and embryo transfer using Folltropin ${ }^{\circledR}-\mathrm{V}$. The main data set examined all available records with respect to treatment number, number of treatments in a sequence, the 
status of mothers/donors and whether they were a product of embryo transfer, the number of known calves produced from embryo transfer and the number of calves born naturally to embryo donors. A smaller data set was based on known family relationships from four generations for the same endpoints. Statistical analyses, based on analyses of variance, revealed no significant differences among the observed variables (numbers of embryo recovery, calves by embryo transfer, natural born calves, etc.) as a consequence of the independent variables. We concluded that there was no evidence of adverse effects of treatment, or repeated treatment of donor cows with Folltropin ${ }^{\circledR}-\mathrm{V}$, on reproductive performance, embryo production or the resulting offspring.

Although it is generally believed that some LH is required for successful superovulation, endogenous LH levels may be adequate. Looney et al. [28] reported that recombinantly-produced bFSH induced high superovulatory responses without the addition of exogenous LH. In addition, fertilization rates exceeded $95 \%$ and viable embryo rates exceeded $85 \%$. These data suggest that LH is not needed in superovulatory preparations and that embryo quality may be superior with pure FSH. The very high fertilization rates and transferable embryo rates in the absence of exogenous $\mathrm{LH}$ tend to suggest that the administration of $\mathrm{LH}$, at any dose, may be detrimental to embryo quality.
An experiment was designed to determine the effects of exogenously administered LH on the superovulatory response in Bos taurus cattle [43]. Cross-breed beef cows were randomly placed into one of four treatment groups to be superstimulated with a total dose of pFSH equivalent to $400 \mathrm{mg}$ NIH-FSH-P1 over 4 days. Cows in Group I received a standard porcine pituitary extract much like FSH-P (100\% LH), whereas cows in Group II received a preparation with approximately $68 \% \mathrm{LH}$ removed $(32 \% \mathrm{LH})$, cows in Group III received a preparation with approximately $84 \% \mathrm{LH}$ removed $(16 \% \mathrm{LH}-$ equivalent to Folltropin $\left.{ }^{\circledR}-\mathrm{V}\right)$, and cows in Group IV received a preparation with $98 \%$ LH removed (Pure FSH). Superovulatory responses clearly divided these cows into two distinct groups (Tab. I); those with high LH (Groups I and II) and those with low LH (Groups III and IV). Overall, there were more ovulations, ova/embryos collected $(P<0.05)$, and there tended to be more fertilized ova $(P<0.07)$ in the two groups with the least LH (Groups III and IV). With the doses used in this experiment, there was no effect of LH on ova/embryo quality. The results demonstrate that $\mathrm{LH}$ within $\mathrm{FSH}$ preparations affects the superovulatory response and that the maximum acceptable level of LH appears to be between 15 and $20 \%$.

In yet another experiment involving Brahman-cross (Bos indicus) heifers superstimulated with $400 \mathrm{mg}$ NIH-FSH-P1

Table I. Superovulatory response of Bos taurus cows superstimulated with FSH (400 mg NIH-FSH-P1) and varying amounts of LH [43].

\begin{tabular}{lllllllll}
\hline & \multicolumn{9}{c}{ Ova/embryos } \\
\cline { 2 - 9 } Group & $n$ & CL & Total & Fert & $(\%)$ & Trans & $(\%)$ \\
\hline I & $(100 \%$ LH $)$ & 21 & $10.2^{\mathrm{a}}$ & $7.3^{\mathrm{a}}$ & $5.3^{\mathrm{c}}$ & $(73)$ & 4.0 & $(55)$ \\
II $\quad(32 \%$ LH $)$ & 20 & $11.1^{\mathrm{a}}$ & $6.4^{\mathrm{a}}$ & $4.6^{\mathrm{c}}$ & $(72)$ & 3.9 & $(61)$ \\
III $\quad(16 \%$ LH) & 20 & $15.6^{\mathrm{b}}$ & $13.6^{\mathrm{b}}$ & $9.7^{\mathrm{d}}$ & $(71)$ & 7.7 & $(57)$ \\
IV $\quad$ (Pure FSH) & 20 & $17.2^{\mathrm{b}}$ & $13.2^{\mathrm{b}}$ & $8.3^{\mathrm{d}}$ & $(63)$ & 5.5 & $(42)$ \\
\hline
\end{tabular}

Means with different superscripts are different ( ${ }^{\mathrm{ab}} P<0.05$; ${ }^{\mathrm{cd}} P<0.07$ ). 
Table II. Superovulatory responses of Bos indicus heifers, superstimulated with FSH (400 mg NIHFSH-P1) and varying amounts of LH [42].

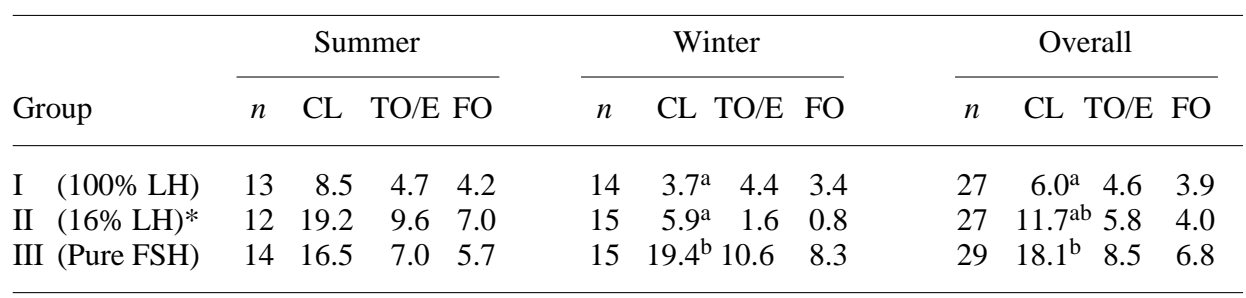

${ }^{\mathrm{ab}}$ Means within a column with superscripts not in common are different $(P<0.05)$.

* Group II differed between the summer and winter $(P<0.05)$.

containing $100 \%, 16 \%$ or $2 \%$ LH (Pure FSH), Tribulo et al. [42] reported that the more purified preparations caused the higher superovulatory response (Tab. II). Overall, the most purified preparation (Group III) induced more CL and tended to result in more ova/embryos and fertilized ova when compared to the least purified preparation (Group I). The intermediate preparation (16\% LH; group II) induced an intermediate response. However, there were obvious seasonal effects. Responses with pure FSH and $16 \% \mathrm{LH}$ were superior to the crude extract (100\% LH) during summer months, but only the pure FSH was more efficacious during winter months.

These results appear to contradict the findings of Page et al. [39] who reported that superovulation and embryo quality in Holstein heifers was not affected by $\mathrm{LH}$ levels in cool weather; whereas a low LH preparation (Folltropin ${ }^{\circledR}-\mathrm{V}$ ) yielded more $\mathrm{CL}$ and significantly more fertilized ova and transferable embryos during heat stress. It becomes apparent that stress is the common factor. Bos taurus breeds likely find summer heat stressful, whereas Bos indicus breeds likely find winter temperatures stressful. In either case, the more purified extracts resulted in greater superovulatory responses during conditions of stress.

We have also investigated the use of Folltropin ${ }^{\circledR}-\mathrm{V}$ as a single bolus injection for superstimulation of cattle. A single subcutaneous injection of Folltropin ${ }^{\circledR}-\mathrm{V}$ at a dose equivalent to $400 \mathrm{mg}$ NIH-FSH-P1 resulted in a superovulatory response equivalent to that of a 4 day, twice daily intramuscular treatment regimen [10]. During the course of these studies, it was found that a more consistently high superovulatory response occurred when the subcutaneous injection was made behind the shoulder as opposed to the neck region. We have since found that splitting the single subcutaneous dose (day 0-75\%; day 2-25\%) improved the results in cows with little subcutaneous fat [29], and we have preliminary results suggesting that the ischiorectal fossa may be an alternative site for a single injection of $\mathrm{FSH}$ [17]. In fact, anything that results in the increased absorption of FSH (e.g. intramuscular injection or injection in the neck region of lean cows) resulted in a reduced superovulatory response. Although Folltropin ${ }^{\circledR}-\mathrm{V}$ has been reported to have more than $80 \%$ of $\mathrm{LH}$ removed, there may be sufficient $\mathrm{LH}$ remaining to result in an over-dose when administered in a single bolus injection or when the absorption rate is increased.

A single bolus subcutaneous injection of Folltropin ${ }^{\circledR}-\mathrm{V}$ has much to offer superstimulatory treatment protocols, especially when twice daily treatments may result in stress which may suppress superovulatory response. In one study involving Bos indicus heifers, a single subcutaneous injection of Folltropin ${ }^{\circledR}-\mathrm{V}$ resulted in a significantly greater superovulatory response than a twice daily, four-day treatment schedule [10]. We attributed the difference to the stress associated with twice daily treatments and handling. 
When comparing experiments, the route of administration must also be considered (reviewed in [5]). We have observed that twice daily intramuscular injections of Folltropin ${ }^{\circledR}-\mathrm{V}$ resulted in a significantly higher superovulatory response than twice daily subcutaneous injections. We have also demonstrated that a single intramuscular injection resulted in higher circulating $\mathrm{FSH}$ levels than did a single subcutaneous injection [5]. However, the subcutaneous injection resulted in a more prolonged increase in FSH levels and a significantly improved superovulatory response [10].

Individual studies often show little or no difference in the results among the various gonadotrophins used for superovulation in the cow. It is also obvious that breed, environment, nutrition and the individual animal response are factors which complicate ovarian stimulation. The role of stress has not been well documented, and more studies are required to understand the stresscortisol-cytokine-hormone effects on reproductive performance and superovulation.

\section{ANIMAL INFLUENCES ON SUPEROVULATION}

With a better understanding of ovarian function has come a greater capability of controlling it. Our expanding knowledge of the roles of the CL and follicular waves in the bovine estrous cycle has resulted in renewed enthusiasm about the prospects of precise synchronization of estrus and ovulation. The intention of the following discourse is to provide an overview of normal ovarian events in cattle, and to discuss how these events impact on the effectiveness of superstimulation regimens. We hypothesized that ovarian response to exogenous stimulation is contingent upon the physiologic status of the ovaries at the time of superstimulation.

\subsection{Ovarian follicular wave dynamics}

It has been shown that greater than $95 \%$ of bovine estrous cycles are composed of either two or three follicular waves (reported by Adams, Fortune, Ginther, Roche and Boland, and others; reviewed by Adams in [2]). Single-wave cycles have been reported in heifers at the time of puberty and in mature cows during the first interovulatory interval after calving. Four-wave cycles are observed occasionally in Bos indicus cattle [40]. The proportion of animals with twoversus three-wave cycles varies among reports; some report a majority of two-wave cycles and others report a majority of threewave cycles while others have observed a more even distribution (reviewed in [2]). Although the subject has not been systematically studied, there does not appear to be a clear breed- or age-specific preference for one follicular wave pattern over the other, nor is there any apparent difference in fertility [4]. In a study of the effects of nutrition on follicular dynamics, cattle fed a low energy ration had a greater proportion of three-wave cycles than those fed higher energy rations [37]. Preliminary data collected from 9 heifers during their first 2 years suggest that the pattern is repeatable within individuals (Adams, unpublished). In another study in Bos indicus cattle, four of 25 cows had four follicular waves per cycle; one cow changed from four waves in the spring to three waves in the autumn. The evolutionary reason for a two- or a three-wave cycle, or for the wave-like pattern itself, is unclear; however, the differences in wave patterns are distinct and they have clear implications regarding ovarian synchronization and superstimulation.

Simply put, the wave pattern of follicular development refers to periodic, synchronous growth of a group of antral follicles. In cattle, follicle wave emergence is characterized by the sudden (within 1 to 2 days) growth of more than 20 small follicles that are initially detected by ultrasonography at a diameter of 3 to $4 \mathrm{~mm}$ [2]. For about 2 days, growth rate is similar among follicles of the wave, then one follicle is selected to continue growth (dominant follicle) while the remainder become atretic. In both two- and three-wave estrous cycles, emergence of the 
first follicular wave occurs consistently on the day of ovulation (day 0). Emergence of the second wave occurs on day 9 or 10 for two-wave cycles, and on day 8 or 9 for threewave cycles. In three-wave cycles, a third wave emerges on day 15 or 16 . Successive follicular waves will remain anovulatory until luteolysis occurs. The dominant follicle present at the onset of luteolysis will become the ovulatory follicle, and emergence of the next wave is delayed until the day of ovulation. The CL begins to regress earlier in two-wave cycles (day 16) than in three-wave cycles (day 19) resulting in a correspondingly shorter estrous cycle (20 days vs. 23 days, respectively). Hence, estrous cycle length may provide a clue to the numbers of follicular waves that a given cow has within each cycle.

\subsection{Role of gonadotrophins in follicular wave development}

The mechanism involved with follicular wave dynamics is based on differential responsiveness of the ovary to $\mathrm{FSH}$ and $\mathrm{LH}$ [2]. Periodic surges in circulating concentrations of FSH are responsible for eliciting follicular wave emergence; hence, cows with two-wave cycles have two FSH surges and three-wave cycles have three surges [3]. Circulating FSH is subsequently suppressed by negative feedback by estradiol and inhibin from the emerging follicles and the following nadir in FSH effectively prevents new wave emergence. The transient rise in FSH permits sufficient follicular growth so that some follicles acquire LH responsiveness which allows survival without FSH. At the time of follicle selection, 2 or 3 days after wave emergence, FSH is declining rapidly. The follicle destined to become dominant apparently acquires receptors for $\mathrm{LH}$ and has the competitive advantage over follicles destined to becoming subordinate. However, LH responsiveness and the ability to become a dominant follicle likely represents a quantitative rather than an absolute difference between follicles in a wave. Subordinate follicles can become dominant if the original dominant follicle is removed or if exogenous FSH is supplied [2]. Furthermore, the competition for LH among multiple dominant follicles (i.e., superstimulated with $\mathrm{FSH}$ ) is apparent by the smaller maximum diameter attained compared to single dominant follicles. Continued suppression of LH as a consequence of luteal-phase progesterone secretion causes atresia of the dominant follicle, and FSH is again allowed to surge. This surge has no effect on the dying dominant follicle, but is responsible for eliciting the emergence of the next wave. The ovarian cycle then repeats itself. Relief from progestational suppression (i.e., luteolysis) allows LH pulse frequency to increase, permitting further growth of the dominant follicle and dramatically higher circulating concentrations of estradiol, which results in a surge of LH followed by ovulation.

The conventional protocol of initiating ovarian superstimulation during mid-cycle (8 to 12 days after estrus) was arrived at empirically, but studies in which a lesser response to superstimulatory treatments initiated early in the estrous cycle ( 2 to 6 days after estrus) vs. later ( 9 to 11 days after estrus) validated the convention $[22,26]$. The reason for the relative success of the conventional approach may be explained by what we now understand about follicular dynamics.

We hypothesized that the superstimulatory response would be greater if the treatment was initiated before selection of a dominant follicle. In an initial study, recombinant bFSH given to heifers before the time of selection (day 1 , ovulation $=$ day 0 ) resulted in more ovulations than that given after the time of selection (day 5) of the dominant follicle of Wave 1 [1]. A subsequent study was done to determine if exogenous FSH given at the expected time of the endogenous wave-eliciting FSH surge had a positive effect on the superstimulatory response [38]. The endogenous surge in FSH was expected to peak 1 day before wave emergence, so 
the superstimulatory treatments were initiated on the day before, the day of, or 1 or 2 days after wave emergence. Significantly more follicles were recruited and more ovulations occurred when treatment began on the day of, or the day before, follicular wave emergence.

In a direct comparison between waves, the results of another study did not reveal any difference in the number of large follicles recruited, the number of ovulations induced, or the number of ova/embryos recovered in heifers in which superstimulation was initiated on the day of emergence of Wave 1 or Wave 2 (reviewed in [1]). Consistent with the previous study [38], when treatment was initiated $\geq 1$ day after wave emergence, the superstimulatory response was reduced. These data suggest that superovulation may be induced with equal efficacy when treatment is initiated during the first or second follicular waves, and that the superstimulatory response is enhanced if treatment is initiated at the time of wave emergence.

Based on the duration of the developmental phases of the dominant follicle in two-wave and three-wave interovulatory intervals, the probability at any given time that the dominant follicle is not functionally dominant is approximately $30 \%$ (6 of 20 days) for two-wave heifers and 35\% (8 of 23 days) for three-wave heifers. More importantly, only $20 \%$ (4 or 5 days) of the estrous cycle is available for initiating treatment at the time of follicular wave emergence. Therefore, $80 \%$ of the cycle is not conducive to an optimal superovulatory response. To obviate these problems, studies have been done to determine if superstimulation subsequent to elective induction of follicular wave emergence could be used with equal efficacy to the conventional protocol.

One approach involved transvaginal ultrasound-guided follicle ablation to synchronize wave emergence among heifers at random stages of the cycle followed by the insertion of a progestogen implant and treatment with Folltropin ${ }^{\circledR}-\mathrm{V} 1$ day after ablation, and PGF 48 and 60 h later [9]. Non-ablated control heifers were given Folltropin ${ }^{\circledR}-\mathrm{V} 8$ to 12 days after estrus. Combined over two experiments (Tab. III), there was no difference in the superovulatory response between the ablated and nonablated groups. In another study, Bungartz and Niemann [13] obtained a significantly higher superovulatory response when the dominant follicle was ablated 2 days before initiating gondadotrophin treatments. More recently, we showed that the ablation of the two largest follicles at random stages of the cycle will ensure that the dominant follicle is removed and a new wave will emerge 1 to 2 days later [8].

Another approach to the synchronization of follicular wave emergence for superovulation involves an injection of $5 \mathrm{mg}$

Table III. Response in control heifers superstimulated between days 8 and 12 of the cycle compared to synchronization of wave emergence by follicle ablation or progestogen + estradiol $(\mathrm{P}+\mathrm{E})[9,11]$.

\begin{tabular}{lrrrrr}
\hline & \multicolumn{2}{c}{$\begin{array}{c}\text { Ablation-induced } \\
\text { wave synchrony }\end{array}$} & & \multicolumn{2}{c}{$\begin{array}{c}\text { Steroid-induced } \\
\text { wave synchrony }\end{array}$} \\
\cline { 2 - 3 } \cline { 5 - 6 } \cline { 5 - 6 } & Control & Ablation & & Control & $\mathrm{P}+\mathrm{E}$ \\
\hline No. of heifers & 35 & 60 & & 52 & 56 \\
CL & 22.9 & 18.6 & & 23.7 & 24.3 \\
Total ova/embryos & 10.1 & 9.8 & & 12.3 & 12.4 \\
Fertilized ova & 7.3 & 7.8 & & 7.9 & 9.3 \\
Transferable embryos & 5.4 & 5.6 & & 4.9 & 5.2 \\
\hline
\end{tabular}


estradiol-17 $\beta$ after the insertion of a progestogen implant, followed by the administration of Folltropin ${ }^{\circledR}-\mathrm{V}$ beginning 4 days after estradiol treatment $[11,12]$. PGF was given $48 \mathrm{~h}$ after Folltropin ${ }^{\circledR}-\mathrm{V}$ treatment was initiated and the progestogen implant was removed $12 \mathrm{~h}$ after PGF treatment. Control heifers were given the same dose of Folltropin ${ }^{\circledR}-\mathrm{V}$ between 8 and 12 days after estrus. Combined over two experiments (Tab. III), the superovulatory response in the estradiol-treated groups was equivalent to that of the control groups.

Our preferred approach to the synchronization of follicular wave emergence for superstimulation involves an injection of $5 \mathrm{mg}$ estradiol-17 $\beta$ plus $100 \mathrm{mg}$ progesterone at the time of CIDR-B (Bioniche Animal Health) insertion followed by Folltropin ${ }^{\circledR}$-V given as a single or multiple dose beginning 4 days after estradiol treatment [11, 12]. PGF is given $48 \mathrm{~h}$ after Folltropin ${ }^{\circledR}-\mathrm{V}$ treatment is initiated and the CIDR-B is removed $12 \mathrm{~h}$ later. Combined over several experiments, the superovulatory response in the estradioltreated groups is equivalent to or greater than that of control groups superstimulated on days 8 to 12 of the cycle. In a more recent experiment, we compared the synchrony of follicular wave emergence and the superovulatory response after treatment of norgestomet-implanted cows with estradiol$17 \beta$ or estradiol valerate [31]. Follicular wave emergence occurred on days 3 or 4 (mean $=3.6$ days $)$ in all 37 cows treated with estradiol-17 $\beta$, while follicular wave emergence occurred between days 3 and 6 (mean $=5.7$ days) in $68 \%$ of the estradiol valerate-treated cows. Superovulatory response and total ova/embryos collected were also greater in the estradiol-17 $\beta$-treated group. Data suggest that the greater synchrony of follicular wave emergence following treatment with estradiol-17 $\beta$ and progesterone provides an advantage for the elective induction of superovulation. In another study, a dose of $1 \mathrm{mg}$ of estradiol benzoate was as efficacious as $5 \mathrm{mg}$ estradiol-17 $\beta$ in synchronizing follicular wave emergence on day 4 , whereas a dose of $5 \mathrm{mg}$ estradiol benzoate resulted in a mean of 5 days with more variability [14]. Unfortunately, we have not investigated the synchrony of follicular wave emergence following treatment with a reduced dose of estradiol valerate. In any case, these studies demonstrate that elective induction of follicle wave emergence offers the advantage of initiating superstimulatory treatment at a time that is optimal for follicle recruitment. Thus, the full extent of the estrous cycle is available for superstimulation and the need for detecting estrus or ovulation and waiting 8 to 12 days to initiate gonadotropin treatments is eliminated.

It is noteworthy that in studies involving superstimulation coincident with wave emergence, the response to a single bolus injection of Folltropin ${ }^{\circledR}-\mathrm{V}$ was as good or better than the response to a multiple injection scheme. The nadir between FSH surges is responsible for preventing the emergence of a new wave; provision of exogenous FSH during the period of the FSH nadir may result in "break through" growth of small follicles prior to the time of expected new wave emergence (i.e. the effects of dominant follicle suppression were overcome by FSH) (reviewed in [1, 2]). This may explain how large doses of exogenous FSH in conventional superstimulation schemes can overwhelm the endogenous rhythm and mask the wave effect. If superstimulatory treatment is given for a long enough period, follicle recruitment will become apparent, regardless of follicular wave status at the time of gonadotrophin treatment. However, asynchronous recruitment may result in more variability in ovarian follicular response, and in the quantity and quality of oocytes and embryos collected.

\section{ACKNOWLEDGMENTS}

The authors thank numerous colleagues and students for help in these studies and especially Drs. Stan Alkemade and Gabriel Bo with help on the original manuscript. The Canadian 
Association of Animal Breeders, Saskatchewan Agriculture Development Fund, Coopers Agropharm Inc and Bioniche Animal Health provided financial support. Thanks also to Coopers Agropharm Inc, Bioniche Animal Health and Intervet Canada for supplying products used in theses studies.

\section{REFERENCES}

[1] Adams G.P., Control of ovarian follicular wave dynamics in cattle: Implications for synchronization and superstimulation, Theriogenology 41 (1994) 19-24.

[2] Adams G.P., Comparative patterns of follicle development and selection in ruminants, $\mathrm{J}$. Reprod. Fertil. Suppl. 54 (1999) 17-32.

[3] Adams G.P., Matteri R.L., Kastelic J.P., Ko J.C.H., Ginther O.J., Association between surges of follicle stimulating hormone and the emergence of follicular waves in heifers, J. Reprod. Fertil. 94 (1992) 177-188.

[4] Ahmad Nasim, Townsend E.C., Dailey R.A Inskeep E.K., Relationship of hormonal patterns and fertility to occurrence of two or three waves of ovarian follicles, before and after breeding, in beef cows and heifers, Anim. Reprod. Sci. 49 (1997) 13-28.

[5] Alkemade S.J., Murphy B.D., Mapletoft R.J., Superovulation in the cow: Effects of biologica activity of gonadotropins, Proc 12th Ann. Conv. AETA, Portland, Maine, 1993.

[6] Armstrong D.T., Recent advances in superovulation of cattle, Theriogenology 39 (1993) 7-24.

[7] Armstrong D.T., Opavsky M.A., Biological characteristics of a pituitary FSH preparation with reduced LH activity, Theriogenology 25 (1986) 135

[8] Baracaldo M.I., Martinez M.F., Adams G.P., Mapletoft R.J., Superovulatory response following transvaginal follicle ablation in cattle, Theriogenology 53 (2000) 1239-1250.

[9] Bergfelt D.R., Bo G.A., Mapletoft R.J., Adams G.P., Superovulatory response following ablation-induced follicular wave emergence at random stages of the oestrous cycle in cattle, Anim. Reprod. Sci. 49 (1997) 1-12.

[10] Bo G.A., Hockley D.K., Nasser L.F., Mapletoft R.J., Superovulatory response to a single subcutaneous injection of Folltropin- $\mathrm{V}$ in beef cattle, Theriogenology 42 (1994) 963-975.

[11] Bo G.A., Adams G.P., Pierson R.A., Mapletoft R.J., Exogenous control of follicular wave emergence in cattle, Theriogenology 43 (1995) 31-40.

[12] Bo G.A., Baruselli P.S., Moreno D., Cutaia L. Caccia M., Tribulo R., Tribulo H., Mapletoft
R.J., The control of follicular wave development for self-appointed embryo transfer programs in cattle, Theriogenology 57 (2002) 53-72.

[13] Bungartz L., Niemann H., Assessment of the presence of a dominant follicle and selection of dairy cows suitable for superovulation by a single ultrasound examination, J. Reprod. Fertil. 101 (1994) 583-591.

[14] Caccia M., Bo G.A., Follicle wave emergence following treatment of CIDR-B implanted beef cows with estradiol benzoate and progesterone, Theriogenology 49 (1998) 341.

[15] Callesen H., Greve T., Hyttel P., Preovulatory endocrinology and oocyte maturation in superovulated cattle, Theriogenology 25 (1986) 71-86.

[16] Chupin D., Combarnous Y., Procureur R., Antagonistic effect of LH in commercially available gonadotrophins, Theriogenology 25 (1984) 167.

[17] Colazo M.G., Martinez M.F., Deyo C., Carruthers T.D., Kastelic J.P., Mapletoft R.J., Effect of route of administration of dinoprost on pregnancy rate using different protocols for fixed-time artificial insemination, Theriogenology 55 (2001) 243.

[18] Dieleman S.J., Bevers M.M., Vos P.L.A.M. de Loos F.A.M., PMSG/anti-PMSG in cattle: A simple and efficient superovulatory treatment, Theriogenology 39 (1993) 25-42.

[19] Elsden R.P., Nelson L.D., Seidel G.E. Jr., Superovulation of cows with follicle stimulating hormone and pregnant mare's serum gonadotrophin, Theriogenology 9 (1978) 17-26.

[20] Gonzalez A., Lussier J.G., Carruthers T.D., Murphy B.D., Mapletoft R.J., Superovulation of beef heifers with Folltropin. A new FSH preparation containing reduced LH activity, Theriogenology 33 (1990) 519-529.

[21] Gonzalez A., Wang H., Carruthers T.D., Murphy B.D., Mapletoft R.J., Increased ovulation rates in PMSG-stimulated beef heifers treated with a monoclonal PMSG antibody, Theriogenology 33 (1994) 519-529.

[22] Goulding D., Williams D.H., Roche J.F., Boland M.P., Factors affecting superovulation in heifers treated with PMSG, Theriogenology 45 (1996) 765-773.

[23] Greve T., Callesen H., Hyttel P., Endocrine profiles and egg quality in the superovulated cow, Nord. Vet. Med. 35 (1983) 408-421.

[24] Hasler J.F., McCauley A.D., Schermerhorn E.C., Foote R.H., Superovulatory responses of Holstein cows, Theriogenology 19 (1983) 83-99.

[25] Lerner S.P., Thayne W.V., Baker R.D., Hensche T., Meredith S., Inskeep E.K., Dailey R.A., Lewis P.E., Butcher R.L., Age, dose of FSH and other factors affecting superovulation in Holstein cows, J. Anim. Sci. 63 (1986) 176-183. 
[26] Lindsell C.E., Murphy B.D., Mapletoft R.J., Superovulatory and endocrine responses in heifers treated with FSH at different stages of the estrous cycle, Theriogenology 26 (1986) 209-219.

[27] Looney C.R., Superovulation in beef females, Proc 5th Ann. Conv. AETA, Fort Worth, Texas, 1986, pp. 16-29.

[28] Looney C.R., Bondioli K.R., Hill K.G., Massey J.M., Superovulation of donor cows with bovine follicle-stimulating hormone (bFSH) produced by recombinant DNA technology, Theriogenology 29 (1988) 271.

[29] Lovie M., Garcia A., Hackett A., Mapletoft R.J., The effect of dose schedule and route of administration on superovulatory response to Folltropin in Holstein cows, Theriogenology 41 (1994) 241

[30] Mapletoft R.J., Pawlyshyn V., Garcia A., Bo G.A., Willmott N., Saunders J., Schmutz S., Comparison of four different gonadotropin treatments for inducing superovulation in cows with 1:29 translocation, Theriogenology 33 (1990) 282

[31] Mapletoft R.J., Martinez M.F., Adams G.P., Kastelic J., Burnley C.A., The effect of estradiol preparation on follicular wave emergence and superovulatory response in norgestometimplanted cattle, Theriogenology 51 (1999) 411

[32] Mikel-Jenson A., Greve T., Madej A., Edqvist L.-E., Endocrine profiles and embryo quality in the PMSG-PGF treated cow, Theriogenology 18 (1982) 33-34.

[33] Monniaux D., Chupin D., Saumande J., Superovulatory responses of cattle, Theriogenology 19 (1983) 55-82.

[34] Moor R.M., Kruip Th.A.M., Green D., Intraovarian control of folliculogenesis: Limits to superovulation?, Theriogenology 21 (1984) 103-116.
[35] Murphy B.D., Martinuk S.D., Equine chorionic gonadotropin, Endocr. Rev. 12 (1991) 27-44.

[36] Murphy B.D., Mapletoft R.J., Manns J., Humphrey W.D., Variability in gonadotrophin preparations as a factor in the superovulatory response, Theriogenology 21 (1984) 117-125.

[37] Murphy M.G., Enright W.J., Crowe M.A. McConnell K., Spicer L.J., Boland M.P., Roche J.F., Effect of dietary intake on pattern of growth of dominant follicles during the estrous cycle in beef heifers, J. Reprod. Fertil. 92 (1991) 333-338.

[38] Nasser L., Adams G.P., Bo G.A., Mapletoft R.J , Ovarian superstimulatory response relative to follicular wave emergence in heifers, Theriogenology 40 (1993) 713-724.

[39] Page R.D., Jordan J.E., Johnson S.K., Superovulation of Holstein heifers under heat stres with FSH-P or Folltropin, Theriogenology 31 (1985) 236.

[40] Rhodes J.M., De'Ath G., Entwistle K.W., Animal and temporal effects on ovarian follicula dynamics in Brahman heifers, Anim. Reprod. Sci. 38 (1995) 265-277.

[41] Saumande J., Chupin D., Mariana J.C., Ortavant R., Mauleon P., Factors affecting the variability of ovulation rates after PMSG stimulation, in: Sreenan J.M. (Ed.), Control of Reproduction in the Cow, Martinus Nijhoff, 1978, pp. 195-224.

[42] Tribulo H., Bo G.A., Jofre F., Carcedo J., Alonso A., Mapletoft R.J., The effect of LH concentration in a porcine pituitary extract and season on superovulatory response of Bos indicus heifers, Theriogenology 35 (1991) 286.

[43] Willmott N., Saunders J., Bo G.A., Palasz A Pierson R.A., Mapletoft R.J., The effect of FSH/LH ratio in pituitary extracts on superovulatory response in the cow, Theriogenology 33 (1990) 347. 